\title{
Flavoured Wine - Fad, Fashion or Trend?
}

\author{
Damien Wilson \\ Sonoma State University, Wine Business Institute, 1801 E Cotati Ave, 94928 Rohnert Park, CA, USA
}

\begin{abstract}
This project was initiated because of the increased diversity in demand across global wine markets. Traditional wine producing countries have experienced strong, recent growth in new categories like flavoured wines, while New world countries create publicity for such innovations and traditional categories like organic wines. Ironically, the amount of publicity afforded such categories is contradictory to market trends, which illustrate growth in categories like Prosecco and red wine blends. Categories like organic, natural and orange wine have numerous endorsers, but actual sales figures suggest such wines are yet to capture the interest of the greater market.

With this divergence between publicity and market behaviour being echoing across the globe, wine producers need to be able to determine whether a new category represents an opportunity to consider a strategic change in business direction. Although publicity has been shown to effect a change in wine consumer behaviour, the conditions surrounding a new wine category's growth from fad, trend and fashion are analysed for the purpose of strategic management. This study extends findings from historical narratives through the use of empirical evidence from both European and New World wine markets. The evidence is contrasted with a contemporary phenomenological experience expressed by influencers within both of those markets, as a means to illustrate the disparity between the contemporary appeal of popular publicity, and the challenges faced by wine producers having to respond to the market reality. This study illustrates that implementing strategic decisions on whether to engage in a new trend, depends on the innovative category being consistent with existing strategy and able to impact the market without reliance on external publicity.
\end{abstract}

\section{Introduction}

Wine markets experience rapid change in the modern era. While traditional wine producing countries suffer the dual challenges of declining domestic consumption and increased fragmentation of the wine offer, new world wine producing countries are struggling to produce the right types of wine, in the right volumes, for the right markets, at the right time. Modern markets are changing at a rapid rate as new wines enter the market, and consumers evaluate whether these new wines are worth attention. However, the pay-offs can be very handsome for the winery(ies) that offer a new wine that captures the market's attention. Examples abound, like the recent trend where Prosecco sales outstripped Champagne in the UK [1], the growth in Red blends in the US market [2], WineAustralia's indication that Sauvignon blanc now leads the Australian market [3] and even the discovery of flavoured wines in France [4]. Each of these wine styles becoming preeminent offers wine producers the opportunity to extract profit from these growing trends. As new wine styles progress from fad, through fashionable, to staple, the wine producer benefits from the market advantages of initially being able to command a price premium, before eventually settling on the benefit of being able to more reliably forecast product demand [5].

However, with these emergent wine styles comes a significant challenge to the typical wine producer. Without even considering the challenges facing wine producers in regions where the production of specific wine styles and grape varieties is controlled, even wine producers in regions of complete production liberty must struggle with the lag-time between changes in production strategy and market release. Accordingly, wine producers would benefit from the knowledge of whether a new category to the market is more likely to linger for an indefinite period, or whether the trend will die a quick death.

Wine producers would be well served with the knowledge of the conditions that contribute to innovations becoming established market trends, and when such trends progress to becoming predictable market behaviours. Following market data can be insightful, but is always conducted after trends have occurred. Forecasts can be made from historical data, but insights on market changes are random guesses, at best. Witness the recent trend in publicity for obscure wine styles like Natural [6], or orange wines [7]. A review of these topics' dedicated newspaper column inches would suggest that such trends are about to take over the market. However, a review of the history between forecasts, and subsequent market trends in the wine sector makes for uncomfortable reading for wine producers.

Consequently, this project utilises a comparative historical narrative method as a means to provide insight on the indicators that best result in an accurate forecast of market trends. This method compares both historical market data and forecasts made by authors on wine market trends. This project concludes with a discussion on global market trends in recent decades, and provides recommendations on how the world's wine producers can best respond to these potential market opportunities in order to implement sound wine production strategy for global wine markets. 


\subsection{Structure of this article}

This article introduces the concept of market trends, and the considerations in forecasting, and responding to forecasts by global wine producers. The manuscript begins with a summary of global wine consumption. Part two of the first section defines the trends in wine consumption behaviour. Specifications are made for areas in which there are differences between the global trend and the regional difference. Explanations are made for explaining the differences, where these are available.

The second section of the manuscript focuses on the factors and influences that are perceived to affect trends in the wine market. Examples are posited in order to emphasise how trends are created, progress and continue or disappear depending on the market's response. This section concludes with a series of research questions on which this study responds.

The following section outlines the methodology used in this study. This project compares the narrative history on the forecast trends in wine consumption with the empirical data on wine consumption patterns. The insight gained from comparing empirical data with forecasts illustrates the differences between expectations and reality.

The final section draws on the implications from the differences between expectations and reality. Conclusions are made on the accuracy of forecasts, and the implications ascribed to wine producers. Shortcomings and further research round out this manuscript.

\section{Market trends}

In recent years, a brief overview of the global market illustrates that all wine markets have changed to a degree [8]. Western Europe has been forced to look at new market opportunities as traditional wine consumers have not proven to be as profitable as forecast, while new markets have opened up around the world.

Traditional wine producing countries have relied on the strategy where consumers actively search for information on wine and wine styles. However, even though wine consumers have expressed a keen interest in wines from traditional wine producing markets, the fact remains that there is a difference between what consumers say they do and what they actually do. Returning to their behaviours, a review of OIV statistics on wine consumption illustrates a substantial change in consumer behaviour in the past generation, and this continuing evolution in consumption patterns appears not to be waning [9].

In the late 1970s, the international wine market attained what is now referred to as 'peak wine'. Wine consumption almost reached the 30 billion Litre mark, and this amount was primarily due to Western Europe being the key market for wine consumption [10]. At that time, in addition to most wine consumers coming from that area, approximately $90 \%$ of global wine exports came from Western Europe [11].

This period wasn't only disappointing for Europe and her wine producers, but grape growers, wine distributors and restaurateurs also began to suffer as wine consumption plummeted across Europe [10]. Throughout the 1980s wine consumption also plummeted in new world markets. However by the early 1990s, wine consumption was already on the increase in New World markets while consumption continued to fall in traditional European markets.

The reasons for New World wine markets experiencing growth while traditional wine markets were declining is difficult to say. However, New World wine producers had had to find new ways to promote and communicate their wines to the global wine market, and there is evidence that restricting the potential growth of New World wine producers' markets had led to these producers adopting an innovative approach to wine business. On the back of the free trade agreement between new world wine producers and the European Union, traditional European labels relying on regions were no longer available to these new World producers. As such, wine producers in countries like United States, Australia and New Zealand were forced to adopt labelling practices that had to both identify the wine in the bottle as well as having to attract new consumers via a non-existent labelling protocol. As a result these wine producers substituted labels indicating the wine's style or the grape varieties used in the wine's production. This new labelling protocol meant the consumers had to learn about grape varieties instead of regions of production.

Over the same period wine consumption patterns in Europe continued to decline. Between 1980 and 2005 data captured on wine consumption in France illustrated a decline of almost 70\% in volume. Where once the French were frequent consumers of wine their consumption patterns over a 25 year period had changed completely. Such a devastating decline in consumption was echoed across Europe. According to Euromonitor [12], not only has wine consumption in Italy, France and Spain declined substantially since the year 2000 , but the value of wine produced those countries has fallen by a similar amount. In fact one of the few components of these countries' wine sectors to have grown over that same period is the number of regional indicators made available to wine producers. Taking France as an example, since the mid 1970s the number of appellations available for communicating the specific region in which a one was made has doubled [11]. So although wine consumption has fallen $70 \%$ and consumers has gone from being regular consumers to occasional consumers of wine, the number of regions from which consumers could choose a French wine became twice as difficult [11].

New World wine markets have not suffered to the same extent. Since the 1980s most wine producing countries outside of Europe suffered an initial decline in wine consumption until the early 90s. Due to this decline in wine consumption, and coupled with the ruling that new World wine producers were forced to drop their use of European regions as part of the labelling protocols used on the wine bottles, a new labelling protocol was born. New World wine producers recognised that they could not label their wines by unknown reasons so they used information about the wine that was common to them. By the mid 1980s new World wine producers were labelling their wines by the grape variety used in their wine's production.

By the early 1990s this new labelling protocol was starting to pay off. Pioneering wine producing countries like Australia, Chile and the United States began pushing their wines into new markets. The familiarity aided wine sales as consumers recognised common grape varieties as they began to discover wine from new countries. These pioneering wine producers introduced new consumers to 
the wine category. A great benefit of this era was that wine began to penetrate the consumer market. The great challenge was encouraging them to buy more wine or to spend more money on it over time.

These new consumers say they want to drink better, buy better, and enjoy better wines, the evidence presented by Euromonitor suggests that wine consumers may say they want to drink wines of better quality but evidence on behaviours illustrate otherwise [13]. Although the nominal value of wine consumed has increased in the past decade, the real value based on inflation and currency fluctuations has fallen over the last 15 years [12]. Consequently it is difficult to say that consumers have increased the amount of money they spend on wine when the evidence suggests that they are spending the same today as they did 15 years ago. All we know is that Global wine consumption is similar today as to how it was 30 years ago, but that we have more than twice the number of consumers today that we had back then. The question of how their consumption patterns change, and to what degree, is an essential part of adapting strategy for wineries to take advantage of that change.

\section{Innovation and scope}

Launching innovations is one way that change can be effected in the wine sector. Innovating to any degree takes time and cost money, and because wine producers tend to have businesses with modest cash flows, the level of innovation in the wine sector tends to be conservative. However because there are large numbers of wine producers in the global market, consumers can be led to believe that the wine sector is comparatively innovative.

Innovating is a way to attract the consumer's attention. In creating attention innovations often generate sales. Even though wine consumption has remained relatively static over the last 35 years, the number of innovations to have been released in the market is substantial. From the creation of new styles, new packaging, new uses, a new forms of distribution wine has seen more innovation in the last generation than for the 300 years prior.

To be categorised as an innovation the new product must be an improvement on the existing product [14]. Further, the innovation must be capable of being diffused to network $[14,15]$. Therefore for wine producers to be successfully innovative they need to understand how their products improve on existing products and they must also be capable of diffusing innovations through their distribution network.

As an example consider the innovations listed in Table 1 below.

These innovations are just an example for the purpose of this article. These examples illustrate both an improvement on existing offers in the market plus they illustrate how broadly they are diffused.

The natural wines category has emerged in recent years. As an innovation it offers benefits to consumers with chemical sensitivities. It also provides its advocates with support for the philosophical question around wine making as an art or science. Enthusiasts of the category are adamant that this wine style should be the destination for all wines.

Natural Wine as a category has a growing network of endorsers. This network suggests that natural wines are a
Table 1. Recent innovations in the wine sector.

\begin{tabular}{|l|l|l|}
\hline Innovation & Improvement & Diffusion \\
\hline Natural Wines & Ethical, Health & $\begin{array}{l}\text { Celebrity } \\
\text { Endorsement, } \\
\text { Motivated } \\
\text { advocates, } \\
\text { On-premise } \\
\text { sales }\end{array}$ \\
\hline Screwcap closures & $\begin{array}{l}\text { Technical, } \\
\text { Convenience }\end{array}$ & $\begin{array}{l}\text { Country } \\
\text { Specific, } \\
\text { Variety-Focused }\end{array}$ \\
\hline Flavoured Wines & $\begin{array}{l}\text { Convenience, } \\
\text { New } \\
\text { customer }\end{array}$ & $\begin{array}{l}\text { Off-premise } \\
\text { retail }\end{array}$ \\
\hline
\end{tabular}

fast growing category, as proposed in recent articles on the topic $[6,16]$. Although it's clear that there's a lot of interest in this innovation, and there's ample support for the category to be diffused broadly, it's less clear as to whether there is much scope for the category to be adopted by consumers.

This scepticism for the adoption of natural wines comes from the fact that there is scant data on the volume of natural wine made or sold across the wine sector. Even with a number of advocates and endorsers of this category, critics will argue that the lack of empirical evidence suggests that there is not great scope for this innovation.

Early adopters generated interest in the category through celebrity and iconography. When Noma, the world's top restaurant based in Denmark, was publicised as having only natural wines on the list the publicity for the natural wine movement increased substantially. However despite the support of a number of celebrities and this famous restaurant the lack of natural wine options in the market and consumer reluctance suggests that publicity got ahead of reality [17].

When a new category is unavailable when consumers look for it, there is a difference between the proposed scope of diffusion and latent consumer demand. Data captured by Euromonitor, Impact, and also taken from observations of supermarket shelves makes no reference to natural wine as a retail category. When publicity suggests a trend, but purchasing options are restricted to less than $1 \%$ of SKUs in a specialist retailer, then the scope of the market needs to be questioned.

Currently it's fair to say the category is innovation but the scope of the category is unclear. As to whether natural wines are merely a fad, or a fashion, or if they will indeed become a staple on the wine market, time has to pass in order for this judgement to be made.

Compare the Natural wine category to the screwcap as an innovation. The screwcap closure has already failed at least once as an innovation [18]. From that lesson the category has developed. The closure presents a technical and convenience benefit when compared to natural corks.

This closure has sceptics and endorsers, similarly to Natural wines. However, the scope of the market for the screwcap is much greater than that for natural wines at the moment. The reason is that a screwcap could be put on any bottle of wine. Thus, the size of the market is much greater than the market for natural wines. With screwcaps estimated to have captured between $12-15 \%$ of the global, 


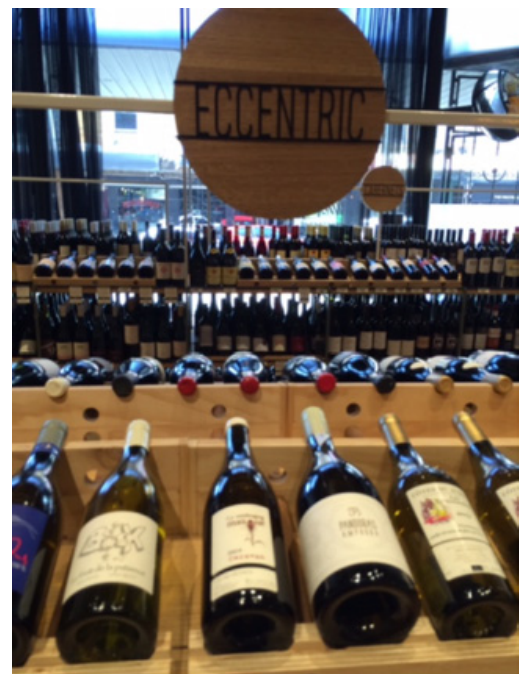

Figure 1. The extent of natural wines available at an independent wine retailer in Australia (Author's picture).

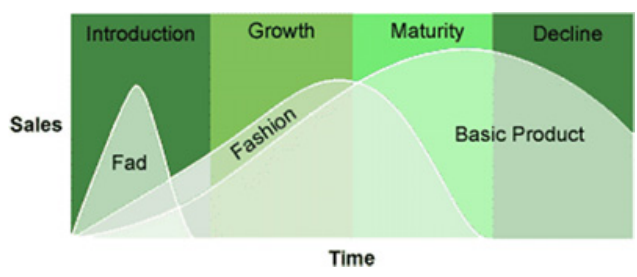

Figure 2. Illustration of trend durations across the product life cycle. Image taken from Istok Pavlovic.

bottled wine market over almost 20 years, there's evidence to suggest that this innovation is moving from fashionable to staple.

\section{Fads, fashion and trends}

The durability of an innovation can help determine how much profit a producer can make over the product life cycle $[19,20]$. Whilst the product life cycle has been researched for decades, since it was first proposed by Rogers, it has changed little in the ensuing period. The product life cycle classifies into components of time from when an innovation is released into the market. These components of time are classified based on the volume of sales that the innovation captures from that point in time. The product life cycle is marked by an introductory stage, across a period where sales are expected to grow rapidly, until demand for the new product plateaus. By overlaying the time over which specific trends endure, the description of a new product being classified as a fad, fashion or Basic product. The challenge in defining whether a new product could be classified as a fad, fashion or basic product is that the time axis in the image above has no element of scale attached to it. As such, evaluating the success of any innovation in the wine sector relies on having a skilled marketer working to analyse whether the product has progressed across product life cycle categories.

\section{Discussion}

With the above trends in mind, it's worth considering how current innovations in the wine market might be classified.
As illustrated earlier, there is a lot of publicity surrounding the emergence of natural wine as a popular category. This style of wine is not clearly defined by its endorsers, and even though proponents decry the need of the wine sector to hark back to the way wine was first made, the classification of natural wine is relatively modern.

However, there is little empirical evidence to suggest that this category could currently be classified beyond a fad or fashion at this stage of its development. Even with the wealth of publicity provided the category, there is little evidence of it being supported on retail shelves. Similarly, even though the historically relevant, orange wines may have strong support in Georgia, in other wine markets throughout the globe, the category 'orange wine' scarcely exists. Classifying it even as a fad may be premature, given that the category has had scant time to emerge from its traditional home market.

The topic of this article, Flavoured wines, is more difficult to evaluate. Many flavoured wines in today's market are merely modern interpretations of a traditional beverage. With this category barely existing in 2010 in France, the growth in sales volume from 500,000 bottles, to $20,000,000$ bottles in 2015 suggests that the category could be either a fad, or fashion. That the wine style has escaped into global markets, coupled with established growth suggests the wine is definitely fashionable. However, the recent plateauing of sales needs to be monitored over subsequent years in order to determine which classification is most appropriate in the long-term.

\section{Conclusions}

This study was concerned with answering the question about whether flavoured wines with classified as a fad, fashion or trend. As explained in text above, trends in the wine sector happen quickly and change rapidly. While early trends in the wind sector were concerned with can use in wine styles and the level of sweetness left the winds more modern trends I' $m$ focused on emerging great varieties and historical wine styles. To ascertain whether a new trend is a fad, fashion or staple of the wine sector the geographic diffusion, time taken to diffuse, and pattern of sales determine the type of trend. As illustrated with the examples above, the scope in which each innovation is evaluated will help determine whether the product is a fad, fashion or staple. Applying these criteria to subsequent innovations will help determine the classification in due course.

\section{References}

[1] AFP, "Prosecco sales overtake champagne in Britain," 20-Aug-2015

[2] C. Huyghe, "The Wine Trend No One's Talking About (Yet): An Insider's View," Forbes, 26-Jan2016. [Online]. Available: http://www.forbes . $\mathrm{com} / \mathrm{sites} /$ cathyhuyghe/2016/01/26/the-win e-trend-no-ones-talking-about-yet-an-ins iders-view/. [Accessed: 18-Sep-2016]

[3] WineAustralia, "Market in Focus - Australia v2.pdf," Wine Australia 2015 Production, Sales and Inventory Survey, Jan. 2016 
[4] C. Dupin, "Fraise, pêche, et même Litchi, les fruits bousculent le marché du vin," lesechos.fr, 01-Sep2015

[5] R. P. Bagozzi and Kyu-Hyun Lee, "Consumer Resistance to, and Acceptance of, Innovations," $A d v$. Consum. Res., vol. 26, no. 1, pp. 218-225, 1999

[6] L. Chan, "Natural Wine Is The Hottest Trend In Winemaking Right Now: Here's Everything You Need To Know," Tech Times, 13-Feb2016

[7] J. Clarke, "13 best orange wines," The Independent, 27-Jul-2015

[8] G. Wittwer, "The Global Wine Market in the decade to 2015 with a focus on Australia and Chile," Centre of Policy Studies, Monash University, General Working Paper G-166, 2010

[9] "2015 OIV report on the world vitivinicultural situation," oiv.int, 2016. [Online]. Available: http://www.oiv.int/en/oiv-life/2015-oivreport-world-vitivinicultural-situationn bsp. [Accessed: 19-Sep-2016]

[10] OIV, "2012 Statistical report on global vitiviniculture." International Organisation of Vine and Wine, 04-Jun-2013

[11] ONIVINS. Office National Interprofessionnel des Vins. Paris (France), C. I. de H. E. A. M. I. A. M. CIHEAM-IAMM, I. N. de la R. A. INRA, and Ministère de l'Agriculture, de la Pêche et de l'Alimentation. SCEES. Service Central des Enquêtes et Etudes Statistique. Paris (France), Panorama de la viticulture. 2006

[12] Euromonitor, "Euromonitor International - Statis tics," Market sizes and historic/forecasts, 2013.
[Online]. Available: http://www.portal.euro monitor.com/Portal/Pages/Statistics/ Statistics . aspx . [Accessed: 17-Feb-2013]

[13] Euromonitor, "Alcoholic Drinks Overview: Thirst for Growth - Part 2 The Category Angle," 08-Nov2015. [Online]. Available: http://0-www . portal . euromonitor.com.iii.sonoma.edu/portal/st atistics/tab. [Accessed: 22-Nov-2015]

[14] C. K. Prahalad, "Bottom of the Pyramid as a Source of Breakthrough Innovations," J. Prod. Innov. Manag., vol. 29, no. 1, pp. 6-12, Jan. 2012

[15] D. Wilson, M. Ingham, and S. Charters, "Innovation Management in the Wine Sector," in Management Innovation, Entrepreneurship and Human Resource Management practices: a global perspective, Chpt. 11., D. Vrontis, G. Sakka, and M. Amirkhanpour, Eds. Lady Stephenson Library: Cambridge Scholars Publishing, 2015, pp. 217-236

[16] R. Haskell, "Why Wild, Chemical-Free, 'Natural' Wines Are Taking the Industry by Storm," Vogue, 21Apr-2016

[17] A. Rosengren, "My Thoughts on Natural Wine," wine, etc., 26-Oct-2013

[18] D. Wilson, "Case Study on the Introduction of the Screwcap to the Wine Market |The Case Centre, for educators," The Case Centre, Case Study 516-5-1, 2016

[19] F. M. Bass, "Empirical Generalizations and Marketing Science: A Personal View," Mark. Sci., vol. 14, no. 3, p. 14, 1995

[20] Goldsmith, "Price Sensitivity and Innovativeness for Fashion Among Korean Consumers," J. Soc. Psychol., vol. 145, no. 5, pp. 501-508, 2005 